\title{
Two Hundred Fifty
}

National Cancer Institute

\section{Source}

National Cancer Institute. Two Hundred Fifty. NCI Thesaurus. Code C69123.

A natural number greater than 249 and less than 251 and the quantity that it denotes. 